\title{
A PROPERTY OF A FUNCTIONAL INCLUSION CONNECTED WITH HYERS-ULAM STABILITY
}

\author{
DORIAN POPA
}

Abstract. We prove that a set-valued map $F: X \rightarrow \mathscr{P}_{0}(Y)$ satisfying the functional inclusion $F(x) \diamond F(y) \subseteq F(x * y)$ admits, in appropriate conditions, a unique selection $f: X \rightarrow Y$ satisfying the functional equation $f(x) \diamond f(y)=f(x * y)$, where $(X, *),(Y, \diamond)$ are square-symmetric grupoids and $\diamond$ is the extension of $\diamond$ to the collection $\mathscr{P}_{0}(Y)$ of all nonempty parts of $Y$. Mathematics subject classification (2000): 39B72, 54C60.

Keywords and phrases: Hyers-Ulam stability; square-symmetric grupoid; functional inclusion.

\section{REFERENCES}

[1] J. ACZÉL, Lectures on functional equations and their applications, Academic Press, 1966.

[2] J. BRZDeK AND A. PietrZy K, A note on stability of the general linear equation, Aequationes Math., 75 (2008), 267-270.

[3] Z. GAJDA, R. GER, Subadditive multifunctions and Hyers-Ulam stability, Numerical Mathematics, 80 (1987), 281-291.

[4] D.H. HYERS, On the stability of the linear functional equation, Proc. Nat. Acad. Sci. USA, 27 (1941), 222-224.

[5] D.H. Hyers, G. Isac, Th.M. Rassias, Stability of functional equations in several variables, Birkhäuser, Boston, 1998.

[6] M. KuczMA, An introduction to the theory of functional equations and inequalities, Cauchy's equation and Jensen inequality, Warszawa-Krákow-Katowice, 1985.

[7] G.H. KIM, Addendum to "On the stability of functional equations on square-symmetric grupoid", Nonlinear Analysis, 62 (2005), 365-381.

[8] K. Nikodem, D. Popa, On selections of general linear inclusions, Publ. Math. Debrecen, 75, 1-2 (2009), 239-249.

[9] Zs. PÁLES, Hyers-Ulam stability of the Cauchy functional equation on square-symmetric grupoids, Publ. Math. Debrecen, 58, 4 (2001), 651-666.

[10] Zs. PÁles, P. Volkmann, R.D. LuCE, Hyers-Ulam stability of functional equations with squaresymmetric operation, Proc. Mat. Acad. Sci. USA, 95 (1998), 12772-12775.

[11] D. PoPA, A stability result for a general linear inclusion, Nonlinear Funct. Anal. Appl., 3 (2004), 405-414.

[12] D. Popa, Functional inclusions on square-symmetric grupoids and Hyers-Ulam stability, Mathematical Inequal. \& Appl., 3 (2004), 419-428.

[13] Th.M. Rassias And J. TABOR, What is left of Hyers-Ulam stability, J. Nat. Geometry, 1 (1992), $65-69$.

[14] J. RÄTZ, On approximately additive mappings, General Inequalities 2 (E.F. Beckenbach, ed.), International Series in Numerical Mathematics, vol. 47, Birkhäuser-Basel-Boston, 1980, 233-251.

[15] A. SMAJdor, Additive selections of superadditive set-valued functions, Aequationes Math., 39 (1990), 121-128.

[16] W. SMAJDOR, Subadditive set-valued functions, Glas. Mat., 21 (1986), 343-348.

[17] W. SMAJdoR, Superadditive set-valued functions and Banach-Steinhaus theorem, Radovi Mat., 3 (1987), 203-214. 